\title{
Novel method for intrafollicular pressure measurements in the rat ovary: increased intrafollicular pressure after hCG stimulation
}

\author{
M. Matousek ${ }^{1}$, C. Carati², B. Gannon ${ }^{2}$ and M. Brännström ${ }^{1}$ \\ ${ }^{1}$ Department of Obstetrics and Gynaecology, Göteborg University, Göteborg, Sweden; and \\ ${ }^{2}$ Microcirculation and Lymphology Laboratory, Department of Anatomy, School of \\ Medicine, Flinders University, Bedford Park, South Australia 5042, Australia
}

The ovulatory process in the rat comprises a period of about 12-15 h, from the time of the preovulatory LH surge to follicular rupture and extrusion of the oocyte. Follicular rupture is most likely caused, at least in part, by decreased tensile strength at the follicular apex due to degradation of collagen fibres of the extracellular matrix. It has been debated whether changes in intrafollicular pressure occur during the ovulatory process and whether such changes facilitate rupture of the follicle. In the present study, rats were primed with equine chorionic gonadotrophin (eCG, $10 \mathrm{iu}$ ) followed by hCG (10 iu) $48 \mathrm{~h}$ later. The intrafollicular pressure in the preovulatory follicle was recorded during $1 \mathrm{~h}$ at distinct time phases of the ovulatory process by use of an active servo-null pressure system based on the proportionality between electrical resistance and pressure within the tip of an inserted micropipette. The basal intrafollicular pressure was $16.6 \pm 1.0 \mathrm{~mm} \mathrm{Hg}$ at the preovulatory phase $(48 \mathrm{~h}$ after eCG) and increased gradually throughout the ovulatory process to $21.4 \pm 2.4 \mathrm{~mm} \mathrm{Hg}$ at $4-7 \mathrm{~h}$ after hCG (midovulatory phase) and $23.9 \pm 1.9 \mathrm{~mm} \mathrm{Hg}$ at $8-12 \mathrm{~h}$ after
hCG (late ovulatory phase; significantly higher $(P<0.01)$ than the preovulatory phase). Short-term peaks of increased pressure, possibly representing contractility, were not detected in follicles of the preovulatory phase, but were seen in most follicles of the mid- and late ovulatory phases. The mean amplitude of the short-term pressure increases was $12.3 \pm 3.2 \mathrm{~mm} \mathrm{Hg}$ and the increases occurred at intervals of $24.7 \pm 3.6 \mathrm{~s}$. These short-term increments in intrafollicular pressure were still present after hysterectomy had been performed. The wall tension index was calculated by measuring the follicular size and estimating the thickness of the follicle wall. The index increased from $93.9 \pm 13.3$ at the preovulatory phase to $207.3 \pm 47.7$ (mid-ovulatory phase) and to significantly higher values at the late ovulatory phase $(320.9 \pm 33.5)$. In conclusion, this study shows that there is an increase in intrafollicular pressure in the ovulating follicle of the rat ovary during the late stages of the ovulatory process, and that short-term increases in intrafollicular pressure occur during the late phase of the ovulatory process. These changes in pressure may be essential for follicular rupture to proceed normally.

\section{Introduction}

The ovulatory process, ending with rupture of the follicle wall and expulsion of the oocyte, is a central event in the reproductive cycle. For rupture to occur, there must be either a decreased tensile strength of the follicle wall or an increase of the pressure inside the follicle, or a combination of these events. The mechanisms underlying follicle rupture have challenged researchers for several hundred years. Up to the mid-1960s, the general consensus was that an increase in intrafollicular pressure resulted in the rupture of the follicle. It was speculated that this increased intrafollicular pressure was due to accumulation of follicular fluid (Schochet, 1916), to transudation of fluid from the blood circulation (Thomsen, 1919), or to enzymatic degra-

Email: markus.matousek@sahlgenska.se

dation of mucopolysaccharides (Zacharie and Jensen, 1958), which would elevate the colloid osmotic pressure. Espey and Coons (1976) reported an increase of follicular volume during the ovulatory process in rabbits, indicating that accumulation of fluid does not necessarily lead to an increase in intrafollicular pressure. Smooth muscle cells have been identified in the preovulatory follicles of several species (Okamura et al., 1971) and spontaneous contractions of these smooth muscle cells may occur (Lipner and Maxwell, 1960). However, recordings of the pressure inside the antrum of preovulatory follicles of the rabbit demonstrated that there was no significant increase in intrafollicular pressure before rupture of the follicle (Espey and Lipner, 1963) and artificially increased intrafollicular pressure by injection of saline into rabbit follicles did not cause rupture (Rondell, 1964).

In light of the findings of these studies, more attention was given to an ovulatory model, in which follicular rupture 
is produced by a decreased tensile strength of the exterior follicular wall. Thus proteolytic enzymes, such as matrix metalloproteinases (MMPs) (Brännström et al., 1988) and plasminogen activators (PAs) (Canipari and Strickland, 1985) have been implicated in the degradation of the collagenous tissue, which is present mainly in the theca externa and tunica albuguinea of the follicle wall.

For methodological reasons, studies that have attempted to measure intrafollicular pressure typically have used animals with larger ovaries than those of rats. Thus intrafollicular pressure has been measured in the preovulatory follicles of cows (Bronson et al., 1979), hamsters (Talbot, 1983) and rabbits (Espey and Lipner, 1963). All of these measurements were accomplished by passive intrafollicular pressure measurements after inserting a large micropipette into the follicular antrum. The main finding of these studies was that there is a relatively constant intrafollicular pressure, between 15 and $20 \mathrm{~mm} \mathrm{Hg}$, during the entire ovulatory process. These direct measurement techniques involved pipettes with a diameter about onetenth of the follicular diameter (Blandau and Rumery, 1963; Rondell, 1964) and most likely are insensitive to subtle changes in intrafollicular pressure occurring during the ovulatory process.

Ovarian-derived mediators such as nitric oxide (Bonello et al., 1996) and endothelins (Acosta et al., 1998) have been implicated in ovulation; thus the decision was made to re-examine intrafollicular pressure during ovulation using a more sensitive technique. In addition, there may be changes in the shape of the follicle and a leakage of follicular fluid from the apex for several hours before follicle rupture in the rat ovary in vitro (Löfman et al., 1989). The rat ovary was chosen as the experimental model and the equine chorionic gonadotrophin (eCG)-hCG-primed immature model was selected, since this is the most extensively studied animal model for research concerning ovulatory mechanisms (Brännström and Janson, 1991). This would enable observations from the present study to be compared in terms of time relationships with results obtained in studies of time-dependent changes of biochemical mediators. The servo-null system was used, which is an active pressure measuring system (Fox and Wiederheim, 1973) that can detect very rapid and small changes in vascular pressure within very small fluid filled spaces.

\section{Materials and Methods}

\section{Animals}

Female Sprague-Dawley rats (Flinders Medical Center Animal House, Bedford Park) aged 26-30 days were given 10 iu eCG (Sigma Company, St Louis, MO) s.c. 48 h before the experiment. Animals were used at the preovulatory phase (48 h after eCG), mid-ovulatory phase (4-7 h after hCG (10 iu) given $48 \mathrm{~h}$ after eCG) or late ovulatory phase (9-12 h after hCG). All experiments were carried out according to the principles of the $\mathrm{NIH}$ guidelines for

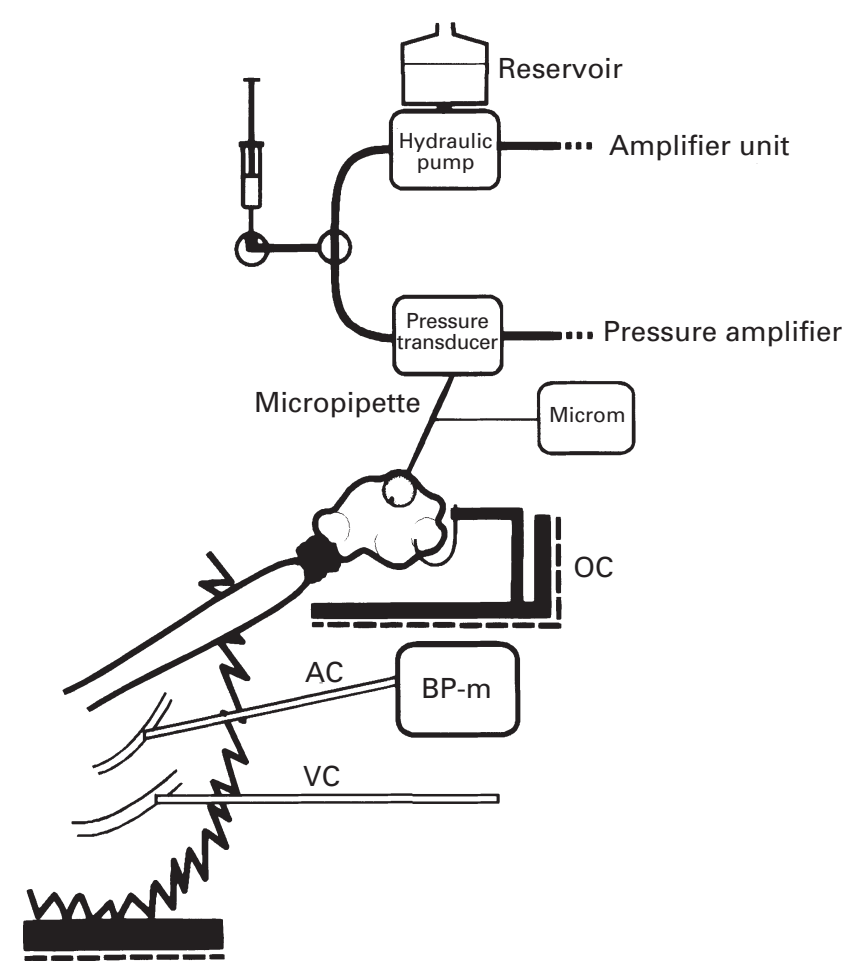

Fig. 1. Schematic representation of the experimental set-up for intrafollicular pressure measurement. The rat is placed on a temperature controlled heating pad with the ovary in an extracorporal position. Catheters are inserted in the vena jugularum (VC: venous catheter) and in the arteria carotis (AC: arterial catheter) for blood pressure measurements (BP-m). The ovary is placed in a temperature controlled organ chamber (OC) and the micropipette of the pressure measurement system (SNS: servonull system) is directed to the preovulatory follicle by a $\mathrm{X}-\mathrm{Y}-\mathrm{Z}$ movable micromanipulator (Microm). The amplifier unit and pressure amplifier record the hydraulic pump pressure and detect rapid changes in pressure. In between the pressure transducer and the hydraulic pump is a syringe that can depressurize the system to atmospheric pressure $(0 \mathrm{~mm} \mathrm{Hg})$ for calibration.

the use of laboratory animals and procedures were approved by the Animal Ethics Committee of Flinders Medical Center.

\section{Preparation of the animals}

The rats were anaesthetized with pentobarbital (60 $\mathrm{mg} \mathrm{kg}^{-1}$, Nembutal; Boehringer Ingelheim, Sydney) and tracheotomies were performed to facilitate spontaneous respiration. Polyethylene catheters (o.d. $0.6 \mathrm{~mm}$; Dural Plastic Engineering, Sydney) were inserted into the right carotid artery for blood pressure recordings (Transducer No. L969; Abbot, Dublin) and into the jugular vein (o.d. $0.8 \mathrm{~mm}$ ) for infusion of drugs, respectively (Fig. 1). An incision of about $20 \mathrm{~mm}$ in length was made on the dorsal midline through the skin and the peritoneal cavity was entered on the left side. The animal was placed on its right side on a heated microscope stage. The right ovary 
and its associated vascular pedicle was taken out of the body cavity and irrigated continuously $\left(1 \mathrm{ml} \mathrm{min}^{-1}\right)$ with heated $\left(37^{\circ} \mathrm{C}\right)$ superfusate $(1 \%$ BSA in PBS, $\mathrm{pH} 7.4)$. This operation does not appear to affect ovarian blood flow (Zachrisson et al., 2000). The ovary with fat pad and distal uterus were covered with transparent plastic film. This procedure was performed to maintain tissue hydration and was based on previous experience of similar recordings on guinea-pig mesenteric lymphatics (McMahon et al., 1994). The bursa of the right ovary was gently opened at a site in between blood vessels and retracted over the ovarian surface to expose the follicles. The follicles were observed via a dissection microscope and the image was captured on video camera and recorded on a videotape recorder for subsequent measurement of follicular size from freeze frame images (McMahon et al., 1994). All measurements of diameter were between the surface of the ovary and the basal transparent edge (corresponding to antral granulosa cells). Animals and tissues were maintained at $37-38^{\circ} \mathrm{C}$ by temperature controlled heating pads and an organ bath. In some experiments, the right uterine horn was surgically isolated from the ovary and oviduct by two ligations and severance in between. A $0.70 \mathrm{~mm}$ cannula (Sterican, Melsungen) was placed inside the abdominal cavity to administer supplementary anaesthesia continuously as required (pentobarbital at $60 \mathrm{mg} \mathrm{kg}^{-1} \mathrm{~h}^{-1}$ ).

\section{Technique for pressure measurement}

The servo-null technique is a well established method of measuring micropressures (Fox and Wiederheim, 1973) and has been used extensively for this purpose (Heslinga et al., 1997; Peti-Peterdi et al., 1998). This active pressure measurement system (Fig. 1) consists of a main processing amplifier unit, a linear hydraulic pump motor, a negative capacitance head stage, a commercial pressure transducer (Transducer No. L969) and the associated hydraulic connections with a 5-10 $\mu \mathrm{m}$ micropipette (World Precision Instruments, Sarasota, FL) connected both hydraulically and electrically.

Micropipettes were made by using standard glass pipettes $(1.0 \mathrm{~mm}$ o.d.) which were pulled in a Sutter model P-87 micropipette puller (Novato, CA) to a tip diameter of $<5 \mu \mathrm{m}$. The tips were broken and ground to $10-15 \mu \mathrm{m}$ in diameter and filled with $2.0 \mathrm{~mol} \mathrm{NaCl}{ }^{-1}$. When pressure at the micropipette tip varies, there is a change in the electrical properties of the fluid in the tip region. This change is detected by a Wheatstone bridge and the servo-null system applies an equal and opposite servo pressure within the micropipette to maintain an unchanged electrical resistance (the null state). This servo pressure is measured by a pressure transducer and is equal to the pressure at the micropipette tip. The gain was calibrated in a calibration chamber as described by Welsh and Segal (1994), followed by calibration of the servo-null system. A micropipette was secured in a pipette holder and pressurized with continuous reference to a mercury manometer. In this system, calibrated micropipettes responded linearly to increases in calibration chamber pressure and provided high-fidelity micropressure recordings.

The micropipette was mounted on an X-Y-Z micromanipulator and placed in the fluid surrounding the ovary. The system offset was adjusted to $0 \mathrm{~mm} \mathrm{Hg}$ (atmospheric pressure) and this baseline was checked regularly between and after measurements. During the experiment, the tip of the servo-null micropipette was inserted into a follicle using the micromanipulator. At the insertion, the experimental set-up permitted visualization of the tip of the pipette penetrating through the wall of the follicle and into the centre of the follicular antrum. Changes in intrafollicular pressure and systemic blood pressure were recorded simultaneously during $1 \mathrm{~h}$ on a computerized A-D system (Dataq Instruments, Akron, $\mathrm{OH}$ ) for subsequent analysis and comparison with the videotaped images.

The follicular wall tension index was calculated from the formula $T=P \times R /(2 \times w)$ ( $T=$ wall tension, $P=$ pressure, $R$ = radius; Rondell, 1970). The wall thickness $(w)$ was estimated to be $40 \mu \mathrm{m}$ at the preovulatory phase and gradually decreased to $30 \mu \mathrm{m}$ at the mid-ovulatory phase and to $20 \mu \mathrm{m}$ at the late ovulatory phase on the basis of previous measurements on histological sections of ovaries in an identical animal model (Brännström et al., 1993; Zackrisson et al., 2000).

\section{Statistical analysis}

The results are presented as the means and standard error of mean (SEM). Statistical differences in intrafollicular pressure and systemic blood pressure were calculated by ANOVA followed by Scheffe's test. A $P$ value of $<0.05$ was considered to be significant for overall (ANOVA) and individual comparisons (Scheffe's test).

\section{Results}

\section{Follicular size and follicular pressure}

The size and intrafollicular pressure of the follicles were measured at three different time points during the ovulatory process. At the preovulatory phase, the diameter of the follicle was $1045 \pm 84 \mu \mathrm{m}$ and the intrafollicular pressure was $16.6 \pm 1.0 \mathrm{~mm} \mathrm{Hg}(n=28$; measurements on separate ovaries and animals) (Figs 2 and 3). In general, the intrafollicular pressure increased (ANOVA, $P<0.005$ ) after hCG stimulation. At a time point about halfway through the ovulatory process (mid-ovulatory phase) the intrafollicular pressure was $21.4 \pm 2.4 \mathrm{~mm} \mathrm{Hg}(n=17)$ and the follicular diameter was $1164 \pm 58 \mu \mathrm{m}$. At the late ovulatory phase, the intrafollicular pressure increased further to $23.9 \pm 1.9 \mathrm{~mm} \mathrm{Hg}(n=14)$, which was significantly $(P<0.01)$ greater than that at the preovulatory phase, but the size of the follicle $(1071 \pm 18 \mu \mathrm{m})$ was similar to that at the earlier time points.

There were no short-term variations in intrafollicular pressure at the preovulatory phase (Fig. 2), but at later 


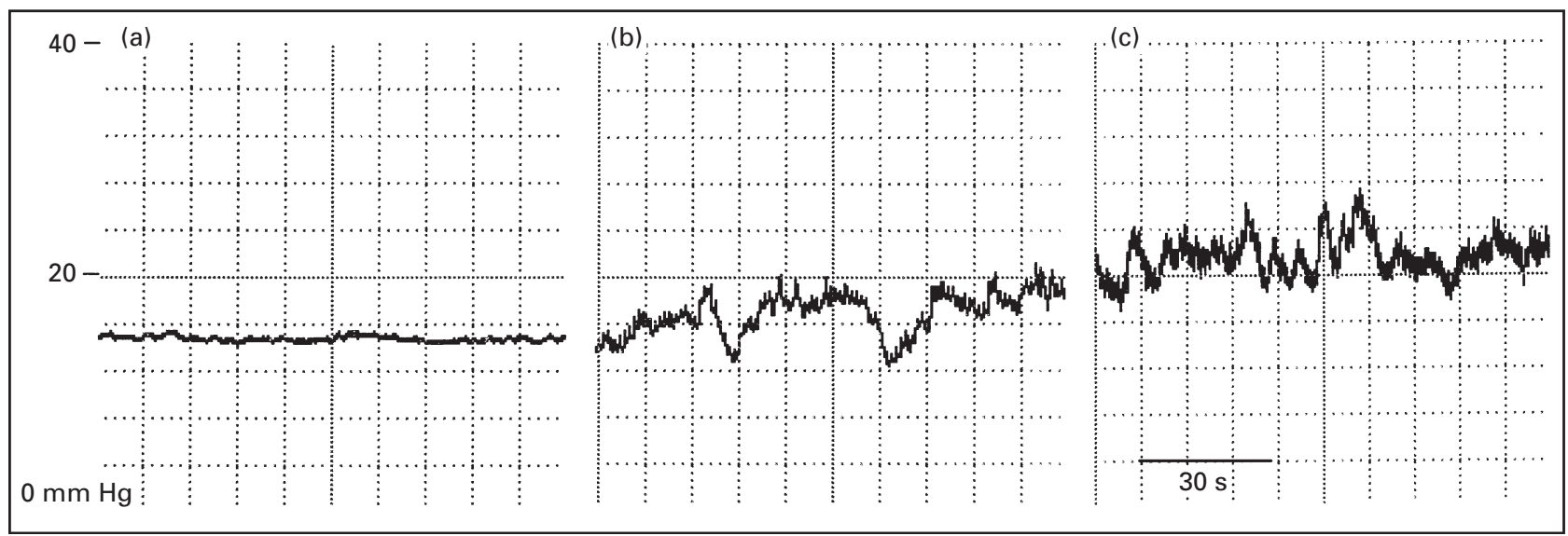

Fig. 2. Typical recordings illustrating the increase in intrafollicular pressure in the rat follicle at different time points. (a) Preovulatory phase represents recording with no hCG stimulation, (b) mid-ovulatory phase 4-7 h after hCG and (c) late ovulatory phase 9-12 h after hCG. Typical short-term increases in intrafollicular pressure are seen at the mid-and late ovulatory phases.

stages spontaneous contractility of the preparation was observed. In the mid-ovulatory group, short-term increases in follicular pressure were observed (Fig. 2) in 10 of 17 recordings and in the late ovulatory group such increases were seen in 6 of 14 recordings. At the late ovulatory stage, hysterectomies were performed on three animals to determine whether the uterus caused the intrafollicular pressure variations either directly or indirectly; however the short-term increases in follicular pressure were still present. The short-term pressure increases showed a mean amplitude of $14.0 \pm 4.5 \mathrm{~mm} \mathrm{Hg}$ and occurred at intervals of $29.2 \pm 2.9 \mathrm{~s}$. In some of the recordings with intrafollicular pressure increases (1/10 mid-ovulatory group; $3 / 6$ late ovulatory group), high frequency amplitude changes $(8.5 \pm 1.3 \mathrm{~mm} \mathrm{Hg})$ were also observed during the contractile state at an interval of $7.4 \pm 1.7 \mathrm{~s}$.

\section{Follicular wall tension index}

The calculated wall tension index increased gradually (ANOVA, $P<0.005$ ) throughout the ovulatory process (Fig. 3) from the preovulatory phase $(93.9 \pm 13.3)$ to the mid-ovulatory phase $(207.3 \pm 47.7)$ and further to the late ovulatory phase $(320.9 \pm 33.5$; significantly higher than preovulatory phase; $P<0.005)$.

\section{Discussion}

The ovulatory process, from the LH surge to follicle rupture, spans about 35-38 h in humans (Andersen et al., 1995) and about $12-15 \mathrm{~h}$ in experimental animals such as rats (Tsafriri and Kracier, 1972). Mammalian ovulation is a complex process initiated by the preovulatory LH surge, and at the ovary involves induction of synthesis and activity of a large number of intraovarian mediators (Brännström et al., 1996). These mediators cause typical biochemical, biophysical and morphological changes in the follicle. Originally, it was thought that the rupture of

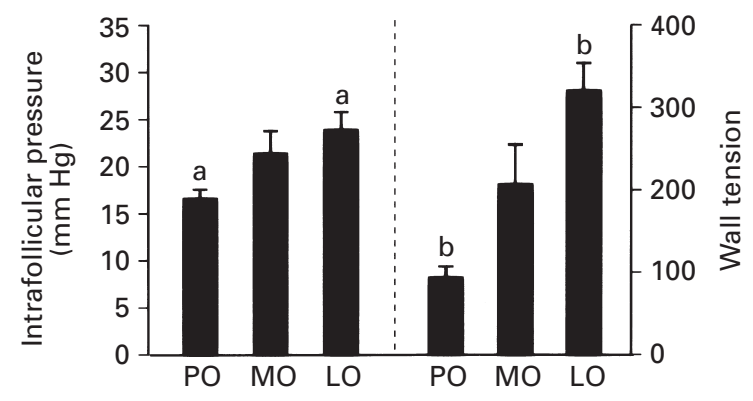

Fig. 3. Means ( \pm SEM) values for intrafollicular pressure (left-hand graph) and wall tension index (right-hand graph) at defined phases of the ovulatory process in rats. Intrafollicular pressure: PO: preovulatory phase $(n=28)$; MO: mid-ovulatory phase $(n=17)$; LO: late ovulatory phase $(n=14)$. Bars with the same letter are significantly different from each other $(P<0.01)$. Wall tension index: PO: preovulatory phase $(n=8)$; MO: midovulatory phase $(n=6)$; LO: late ovulatory phase $(n=7)$. Bars with the same letter are significantly different from each other $(P<0.005)$.

the follicle was caused by an increase in intrafollicular pressure. This increase would cause rupture of the Graafian follicle at the weakest point, the exterior follicular wall, which is not covered by a thick stromal layer. The theory that increased intrafollicular pressure brought about follicular rupture was also substantiated by several studies demonstrating spontaneous contractility of the follicular wall (Guttmacher and Guttmacher, 1921; Lipner and Maxwell, 1960) and the presence of smooth muscle-like cells in the theca externa and stroma of the ovary (Okamura et al., 1971; McReynolds et al., 1973; Talbot, 1991).

However, in the 1960s, studies were performed to measure the intrafollicular pressure in vivo within the follicle of rats (Blandau and Rumery, 1963) and rabbits (Espey and Lipner, 1963; Rondell, 1964) by passive pressure measurement methods. These studies showed the presence 
of constant intrafollicular pressure during ovulation. Signs of contractile activity were also observed in some of the recordings, but not of a magnitude to indicate a direct connection with follicular rupture. Taken together, these findings indicated that the Graafian follicle does not rupture because it has attained a certain size or because pressure within the antrum has reached a certain level. Since these studies, research concerning local ovulatory mechanisms has been directed mainly towards studies of the participation of a number of enzymatic pathways, such as the MMPs (Curry et al., 1992) and serine proteases such as the PAs (Palotie et al., 1987). The general consensus has been that ovulation is caused mainly by degradative changes at the follicular apex.

In the present study, an increase in intrafollicular pressure was observed in the follicles of eCG-hCG primed rats during the ovulatory process and the wall tension index increased concomitantly. In addition, short-term increases in intrafollicular pressure, possibly connected with contractile activity within the wall of the follicle, occurred during the late phases of the ovulatory process.

This is the first report of the use of an active pressure system in the measurement of intrafollicular pressure within preovulatory follicles and this stystem has advantages over the passive systems used previously. The active pressure measurement system uses an active counter pressure system through a servo feedback mechanism, thereby enabling highly sensitive measurements of very minute and rapid changes in follicular pressure. This active system does not have a dead space and reacts almost instantly to both negative and positive pressure changes. Active pressure methodology has been used for measurements of fluid pressures in non-reproductive tissues such as the lymph vessels of gut mesentery of rats (Benoit et al., 1989), the perialveolar lung interstitium of dogs (Glucksberg and Bhattacharya, 1993), the gastric microvasculature of rats (Peti-Peterdi et al., 1998) and the vasculature of the embryo in chickens (Broekhuizen et al., 1999).

An advantage of the methodology used in the present study is that it enables use of micropipettes with very small tip diameters. Micropipettes with tips $<18 \mu \mathrm{m}$ require active pressure transducer systems (Intaglietta, 1973). The rat follicle is approximately $1 \mathrm{~mm}$ in diameter at the preovulatory stage and the size remains relatively stable throughout the ovulatory process, as demonstrated in the present study. The micropipettes used for the pressure measurements had a tip diameter of 10-15 $\mu \mathrm{m}$ and were inserted through the lateral side of the follicle. Thus, the diameter of the pipette is about one-hundredth of that of the follicle and is considerably smaller than those used during passive pressure measurement in rat (o.d. $100 \mu \mathrm{m}$ : Blandau and Rumey, 1963) and rabbit follicles (o.d. $80 \mu \mathrm{m}$ : Rondell 1964; o.d. $25 \mu \mathrm{m}$ : Espey and Lipner, 1963). The large size of the pipettes used with passive systems in these other studies may have influenced the results. One possible type of error is leakage of fluid from the follicle at the interface between the pipette and the tissue. An increase of pipette size from 10 to $100 \mu \mathrm{m}$ will lead to $a>40$-fold increase in the interface and hence leakage may increase proportionally. Thus, a small increase in pressure may not be detected by such a method.

The magnitude of the intrafollicular pressure recorded at the preovulatory phase in the present study $(16.6 \mathrm{~mm}$ $\mathrm{Hg}$ ) is very similar to the intrafollicular pressure in the Graafian follicle of rabbits which was about $17 \mathrm{~mm} \mathrm{Hg}$ at both the preovulatory and late ovulatory phases (Espey and Lipner, 1963). An average intrafollicular pressure of $17 \mathrm{~mm} \mathrm{Hg}$ was also recorded in eCG-hCG treated rats that had received a twofold higher eCG-hCG (Blandau and Rumery, 1963) dose than in the present study. A major difference between the previous results obtained in rabbits (Espey and Lipner, 1963) and rats (Blandau and Rumery, 1963) and those of the present study was that here an increase in intrafollicular pressure at the late stages of ovulation was detected. This increase of about $40 \%$ may not have been detected in the systems with passive pressure measurements because of the larger dead space and the increased viscosity of the follicular fluid (Silvester and Luck, 1999), possibly due to changes in the concentrations of coagulation proteins within the fluid (Yamada and Gentry, 1995). An altered viscosity in some follicles was indicated by the large variations in intrafollicular pressure in pigs (Bronson et al., 1979) in which intrafollicular pressures of $>100 \mathrm{~mm} \mathrm{Hg}$ were recorded in some follicles.

The increase in intrafollicular pressure detected during ovulation in the present study could be due to increased static contraction of the contractile elements of the follicle, as described for the base of the Graafian follicle in hamsters (Martin and Talbot, 1981), or to rhythmic changes in follicular vasculature, as demonstrated in the rat ovary (Zackrisson et al., 2000). It should be noted that in the present study the bursa was opened, which may have affected the pressure. However, since the bursa is thin and flaccid it is likely that the intrabursal pressure would be similar to the intra-abdominal pressure, which is the same as the atmospheric pressure (Dolgor et al., 1998).

Short-term increases in follicular pressure were detected during the late stages of the ovulatory process. It has been suggested that the follicular wall contracts spontaneously (Walles et al., 1975). Structures responsible for this spontaneous contractility are most likely the smooth muscle cells found in the theca externa of several species (Fumagalli et al., 1971; Okamura et al., 1971; Talbot, 1991). Electron microscopy revealed that, in the rat ovarian follicle, smooth muscle cells are localized in concentric layers of the theca externa (O'Shea, 1970). These cells were described as of multiple morphology with either fibroblastlike, muscle-like or an intermediate cell appearance. In addition, there are numerous smooth muscle cells in the stroma surrounding the rat corpus luteum and in clusters of interstitial cells (Amenta et al., 1979).

Studies in vitro on strips of the follicular wall of species such as cows (Walles et al., 1975), hamsters (Talbot and 
Schroeder, 1982) and Japanese quail (Van Nassauw et al., 1993) have demonstrated contractile activity of the follicle wall. In addition, recordings in vivo showed short-term increases in intrafollicular pressure in two of six rabbits with visible bulging of the follicle, indicating contractility of the follicular wall (Espey and Lipner, 1963). In the present study, similar contractile activity, with an amplitude of about $14 \mathrm{~mm} \mathrm{Hg}$ and intervals of about $30 \mathrm{~s}$, was detected in the rat ovary only after hCG. The magnitude and frequency of the contractions were similar to the wave-like pressure changes recorded in vivo in rabbit follicles (Espey and Lipner, 1963). The reason that these intrafollicular pressure increments have not been recorded in most studies may be attributed to the insufficient sensitivity of the passive techniques to the mechanical disturbance of the transmission of contractility as a result of the use of large pipettes.

The reason for the increase in intrafollicular pressure during the late stages of the ovulatory process is unclear, but may be related to biochemical changes in the follicles in which mediators with contractile functions increase. The concentration of prostaglandins increases in follicles as a result of cyclooxygenase 2 (COX-2) induction (Wong and Richards, 1991). One of the prostaglandins that has a role in ovulation is $\mathrm{PGF}_{2 \alpha}$, and intrafollicular concentrations of $\mathrm{PGF}_{2 \alpha}$ peak at $4 \mathrm{~h}$ after hCG in eCG-primed rats (Higuchi et al., 1995). PGF $2 \alpha$ stimulates ovarian contractility in rabbits (Virutamasen et al., 1972) and contractions of arterial smooth muscle in the ovaries of cows (Ford et al., 1977). In addition, the adrenergic neuromuscular stimulatory effect on ovarian smooth muscle cells of cows is enhanced by $\mathrm{PGF}_{2 \alpha}$ (Walles et al., 1986). Bradykinin is another potent mediator that induces contractions, as demonstrated in experiments in vitro on strips of human follicular wall (Hellberg and Norström, 1990). There is also an increase in kinin-generating capacity in the ovary at $4 \mathrm{~h}$ after hCG in rats (Espey et al., 1986). Taken together, these studies indicate that both $\mathrm{PGF}_{2 \alpha}$ and bradykinin may be involved in the mechanisms underlying the increase in intrafollicular pressure, as indicated by the time course of induction and the timing of peak concentrations, which coincide with increased intrafollicular pressure and contractions.

The production of follicular fluid, and hence intrafollicular pressure, is presumably related directly to fluid transudation from the large capillaries of the theca externa (Burr and Davies, 1951) or to increased colloid osmotic pressure in the follicle caused by enzymatic degradation of follicular fluid mucopolysaccharides (Zachariae and Jensen, 1958). The hydrostatic pressure within the capillary bed is dependent on the arterial pressure, the venous pressure and pre- (arterioles) and postcapillary (venules) resistances. The hydrostatic capillary pressure in rats varies due to vasomotion and the regulatory factors described above and is about 15-25 mm Hg (Berne and Levy, 1986). One possible explanation for the increase in intrafollicular pressure, as demonstrated in the present study, is that
LH-hCG-induced ovarian vasodilatation (Janson, 1975), increased permeability (Abisogun et al., 1988) and an increased tissue pressure (Virutamasen et al., 1976) would cause an increase in hydrostatic pressure within the capillary bed of the theca externa, which would increase the intrafollicular pressure.

In the present study the tension index of the follicular wall was calculated. The wall tension index represents the tearing of the follicle wall which attempts to stretch and rupture the follicle. The measurements of wall thickness were based on histological examination of rat ovaries treated under exactly the same conditions (Brännström et al., 1993; Zachrisson et al., 2000). The wall tension index has been used for estimation of tension in other studies (Rondell, 1964) and of tension in other structures of the body such as human arteries (Carallo et al., 1999; Hall et al., 1999). The increase in wall tension index found in the present study was more pronounced than the increase of intrafollicular pressure because the wall tension index is also dependent on the thickness of the follicle wall, which decreases during the ovulatory process.

In conclusion, a gradual increase in intrafollicular pressure was measured during ovulation of the rat follicle and the occurrence of spontaneous contractions was detected within the follicle by an active measurement system. The increased intrafollicular pressure and spontaneous contractions, together with the enzymatic degradation of the extracellular matrix, may be important for rupture of the follicle at ovulation.

The authors would like to thank Ann Wallin for help with illustrations. The study was supported by the Swedish Medical Research Council (Grant No. 11607 to M. Brännström), the Medical Faculty of Göteborg University, Göteborg Medical Society and Hjalmar Svensson Research Foundation.

\section{References}

Abisogun AO, Daphna-Iken D, Reich R, Kranzfelder D and Tsafriri A (1988) Modulatory role of eicosanoids in vascular changes during the preovulatory period of the rat Biology of Reproduction 38 756-762

Acosta TJ, Miyamoto A, Ozawa T, Wijayagunawardane MP and Sato K (1998) Local release of steroid hormones, prostaglandin $E_{2}$ and endothelin-1 from bovine mature follicles in vitro: effects of luteinizing hormone, endothelin-1 and cytokines Biology of Reproduction 59 437-443

Amenta F, Delmas JA, Didio LJA and Motta P (1979) A transmission electron microscopic study of smooth muscle cells in the ovary of rabbits, cats, rats and mice Journal of Submicroscopic Cytology 11 39-52

Andersen AG, Als-Nielsen B, Hornnes PJ and Franch Andersen L (1995) Time interval between chorionic gonadotrophin (hCG) injection to follicular rupture Human Reproduction 10 3202-3205

Benoit JN, Zaweija, DC, Goodman AH and Granger, HJ (1989) Characterisation of intact mesenteric lymphatic pump and its responsiveness to acute edemagenic stress American Journal of Physiology $257 \mathrm{H} 2059-\mathrm{H} 2069$

Berne RM and Levy MN (1986) The microcirculation and lymphatics. In Principles of Physiology pp 301-312 Eds RM Berne RM and MN Levy. Mosby-Year-Book Inc., St Louis

Blandau RJ and Rumery RE (1963) Measurements of intrafollicular pressure in ovulatory and preovulatory follicles of the rat Fertility and Sterility 14 330-341 
Bonello N, McKie K, Jasper M, Andrew L, Ross N, Braybon E, Brännström $\mathbf{M}$ and Norman RJ (1996) Inhibition of nitric oxide: effects on interleukin-1 $\beta$ enhanced ovulation rate, steroid hormones and ovarian leukocyte distribution at ovulation in the rat Biology of Reproduction 54 436-445

Brännström M and Janson P-O (1991) The biochemistry of ovulation. In Ovarian Endocrinology pp 132-166 Ed. SG Hillier. Blackwell Publications, London

Brännström M, Woessner JF, Jr, Koos RD, Sear CHJ and LeMaire WJ (1988) Inhibitors of mammalian tissue collagenase and metalloproteinases suppress ovulation in the perfused rat ovary Endocrinology 122 1715-1721

Brännström M, Mayrhofer G and Robertson SA (1993) Localization of leukocyte subsets in the rat ovary during the periovulatory period Biology of Reproduction 48 277-286

Brännström M, Mikuni M and Peterson CM (1996) Ovulation-associated intraovarian events. In The Ovary: Regulation, Dysfunction and Treatment pp 113-123 Eds M Filicori and C Flamigni. Elsevier Science BV, Amsterdam

Broekhuizen ML, Hogers B, DeRuiter MC, Poelmann RE, Gittenberger-De Groot AC and Wladimiroff JW (1999) Altered hemodynamics in chick embryos after extraembryonic venous obstruction Ultrasound in Obstetrics and Gynecology 13 437-445

Bronson RA, Bryant G, Balk MW and Emanuele N (1979) Intrafollicular pressure within preovulatory follicles of the pig Fertility and Sterility $\mathbf{3 1}$ 205-213

Burr JH, Jr and Davies JI (1951) The vascular system of the rabbit ovary and its relation to ovulation Anatomical Records 111 273-292

Canipari R and Strickland S (1985) Plasminogen activator in the rat ovary. Production and gonadotropin regulation of enzyme in granulosa and thecal cells Journal of Biological Chemistry 260 5121-5125

Carallo C, Irace C, Pujia A, De Franceschi MS, Crescenzo A, Motti C, Cortese C, Mattioli PL and Gnasso A (1999) Evaluation of common carotid hemodynamic forces. Relations with wall thickening Hypertension 34 217-221

Curry TE, Jr, Mann JS, Huang MH and Keeble SC (1992) Gelatinase and proteoglycanase activity during the periovulatory period in the rat Biology of Reproduction 46 256-264

Dolgor B, Kitano S, Yoshida T, Bandoh T, Ninomiya K and Matsumoto T (1998) Vasopressin antagonist improves renal function in a rat model of pneumoperitoneum Journal of Surgical Research 79 109-114

Espey LL and Coons PJ (1976) Factors which influence ovulatory degradation of rabbit ovarian follicles Biology of Reproduction 14 233-245

Espey LL and Lipner H (1963) Measurements of intrafollicular pressures in the rabbit ovary American Journal of Physiology 205 1067-1072

Espey LL, Miller DH and Margolius HS (1986) Ovarian increase in kiningenerating capacity in PMSG/hCG-primed immature rats American Journal of Physiology 251 E362-E365

Ford SP, Weber LJ, Kennick WH and Stormshak F (1977) Response of bovine ovarian arterial smooth muscle to prostaglandin $\mathrm{F}_{2 \alpha}$ and neurotransmitter Journal of Animal Science 45 1091-1095

Fox JR and Wiederheim CA (1973) Characteristics of the servo-controlled micropipette pressure system Microvascular Research 5 324-335

Fumagalli Z, Motta P and Calvieri S (1971) The presence of smooth muscle cells in the ovary of several mammals as seen under the electron microscope Experientia 27 682-683

Glucksberg MR and Bhattacharya J (1993) Effects of vascular pressure on interstitial pressures in the isolated dog lung Journal of Applied Physiology 75 268-272

Guttmacher MS and Guttmacher AF (1921) Morphological and physiological studies on the musculature of the mature Graafian follicle of the sow Johns Hopkins Hospital Bulletin 32 394-399

Hall AJ, Busse EFG, McCarville DJ and Burgess JJ (1999) Aortic wall tension as a predictive factor for aortic aneurysm rupture: improving the selection of patients for abdominal aortic aneurysm repair Annals of Vascular Surgery 14 152-157

Hellberg P and Norström A (1990) Bradykinin induces contractions of the human ovarian follicular wall in vitro. Human Reproduction $\mathbf{5}$ $387-390$
Heslinga JW, Allaart CP, Yin FC and Westerhof N (1997) Effects of contraction, perfusion pressure and length on intramyocardial pressure in the rat papillary muscle American Journal of Physiology 272 $\mathrm{H} 2320-\mathrm{H} 2326$

Higuchi $Y$, Yoshimura T, Tanaka N, Ogino $H$, Sumiyama $M$ and Kawakami S (1995) Different time-course production of peptidic and nonpeptidic leukotrienes and prostaglandins $E_{2}$ and $F_{2 \alpha}$ in the ovary during ovulation in gonadotropin-primed immature rats Prostaglandins 49 131-140

Intaglietta M (1973) Pressure measurements in the microcirculation with active and passive transducers Microvascular Research 5 317-323

Janson P-O (1975) Effects of the luteinizing hormone on blood flow in the follicular rabbit ovary, as measured by radioactive microspheres Acta Endocrinologica 79 122-133

Lipner HJ and Maxwell BA (1960) Hypothesis concerning the role of the follicular contractions in ovulation Science 131 1737-1738

Löfman CO, Brännström M, Holmes PV and Janson P-O (1989) Ovulation in the isolated perfused rat ovary as documented by intravital microscopy Steroids $\mathbf{5 4}$ 481-490

McMahon AM, Carati CJ, Piller NB and Gannon BJ (1994) The effects of radiation on the contractile activity of guinea pig mesenteric lymphatics Lymphology 27 193-200

McReynolds HD, Siraki CM, Bramson PH and Pollock RJ, Jr (1973) Smooth muscle-like cells in ovaries of the hamster and gerbil Zellforschung 140 1-8

Martin GG and Talbot P (1981) The role of follicular smooth muscle cells in hamster ovulation Journal of Experimental Zoology 216 469-482

Okamura H, Virutamasen P, Wright KH and Wallach EE (1971) Ovarian smooth muscle in the human being, rabbit and cat American Journal of Obstetrics and Gynecology 112 183-191

O'Shea JD (1970) An ultrastructural study of smooth muscle-like cells in the theca externa of ovarian follicles in the rat Anatomical Records 167 127-137

Palotie A, Salo T, Vihko KK, Peltonen L and Rajaniemi H (1987) Types I and IV collagenolytic and plasminogen activator activities in preovulatory ovarian follicles Journal of Cellular Biochemistry 34 101-112

Peti-Peterdi J, Hamar P, Kovacs G and Rosivall L (1998) Direct in vivo measurement of gastric microvascular pressures in the rat Microvascular Research 55 223-229

Rondell P (1964) Follicular pressure and distensibility in ovulation American Journal of Physiology 207 590-594

Rondell P (1970) Biophysical aspects of ovulation Biology of Reproduction 2 64-89

Schochet SS (1916) A suggestion as to the process of ovulation and ovarian cyst formation. A preliminary report Anatomical Records $\mathbf{1 0}$ $447-457$

Silvester LM and Luck MR (1999) Distribution of extracellular matrix components in the developing ruminant corpus luteum: a wound repair hypothesis for luteinization Journal of Reproduction and Fertility 116 187-198

Talbot P (1983) Intrafollicular pressure promotes partial evacuation of the antrum during hamster ovulation in vitro. Journal of Experimental Zoology 226 129-135

Talbot P (1991) Muscular apparatus of the ovarian follicle. In Ultrastructure of the Ovary pp 129-141 Eds G Familiari, S Makabe and PM Motta. Kluwer Academic Publishers, Amsterdam

Talbot P and Schroeder PC (1982) 5-Hydroxytryptamine causes contraction of smooth muscle cells in preovulatory hamster follicles Journal of Experimental Zoology 224 427-436

Thomsen A (1919) The ripe human Graafian follicle, together with some suggestions as to its mode of rupture Journal of Anatomy 54 1-40

Tsafriri A and Kracier PF (1972) The time sequence of ovum maturation in the rat Journal of Reproduction and Fertility 29 387-393

Van Nassauw L, Sys SU, Harrisson F and Callebaut M (1993) In vitro study of the contractility of the wall of the preovulatory follicle in the Japanese quail Biology of Reproduction 49 359-364

Virutamasen P, Wright $\mathbf{K H}$ and Wallach EE (1972) Effects of prostaglandins $E_{2}$ and $F_{2 \alpha}$ on ovarian contractility in the rabbit Fertility and Sterility 9 675-682 
Virutamasen P, Smitasiri Y and Fuchs A-R (1976) Intraovarian pressure changes during ovulation in rabbits Fertility and Sterility 27 188-196

Walles B, Edvinsson L, Falck B, Owman Ch, Sjöberg N-O and Svensson KG (1975) Evidence for a neuromuscular mechanism involved in the contractility of the ovarian follicular wall: flourescence and electron microscopy and effects of tyramine on follicle strips Biology of Reproduction 12 239-248

Walles B, Owman C, Schmidt G and Sjöberg N-O (1986) Evidence for a role of prostaglandins in the adrenergic neuromuscular mechanism of the ovarian follicle wall Neuroendocrinology 43 18-23

Welsh DG and Segal SS (1994) A holder and calibration chamber for micropressure measurements Microvascular Research 48 403-405

Wong WYL and Richards JS (1991) Evidence for two antigenically distinct molecular weight variants of prostaglandin $\mathrm{H}$ synthase in the rat ovary Molecular Endocrinology 5 1269-1279
Yamada M and Gentry PA (1995) Hemostatic profile of bovine ovarian follicular fluid Canadian Journal of Physiology and Pharmacology 73 624-629

Zacharie F and Jensen CE (1958) Studies on the mechanism of ovulation. Histochemical and physico-chemical investigations on genuine follicular fluid Acta Endocrinologica 27 343-355

Zackrisson U, Mikuni M, Peterson MC, Nilsson B, Janson P-O and Brännström M (2000) Evidence for the involvement of blood flowrelated mechanisms in the ovulatory process of the rat Human Reproduction 15 264-272

Received 17 July 2000.

Accepted 2 October 2000. 